\title{
Análise da gestão dos recursos hídricos no município de Erechim
}

Analysis of water management resources in the municipality of Erechim

\author{
Lidiane Bernardi
}

Gestão Ambiental em Escolas Públicas do município de Erechim, 2012 - RS - Brasil

\begin{abstract}
Resumo
Este trabalho teve como premissa analisar o status atual da gestão dos recursos hídricos no município de Erechim (RS) com base nos planos de manejo, dados estatísticos, históricos e informações coletadas junto a gestores responsáveis pelas instituições legais que respondem pelas políticas públicas ambientais do município tais como Secretaria Municipal de Meio Ambiente (SMMA), Prefeitura Municipal, Comitê de Bacia Hidrográfica Apuaê Inhandava (CBHAI), Comitê de Bacia Hidrográfica Passo Fundo (CBHPF), Conselho Municipal de Proteção ao Meio Ambiente (COMPAM) e Corsan. Os resultados deste estudo passaram pelo entendimento das propostas dos planos municipais e com a pesquisa de campo pode-se observar que o município conta com toda a estrutura física, institucional e legal e todos os elementos necessários para o gerenciamento do meio ambiente, no entanto estes órgãos interagem pouco e as ações de educação ambiental são realizadas de forma isolada. Quanto ao uso dos instrumentos de gestão observou-se que o município, através do CBHAI elaborou o Plano de Ações em Recursos Hídricos, Enquadramento dos Corpos Hídricos em classe de usos preponderantes e já deu andamento para instalar no município a Cobrança pelo uso da água. O município, através da Secretaria Municipal de Meio Ambiente (SMMA), já utiliza o Licenciamento Ambiental e também elaborou os Planos Ambientais Municipais, porém os mesmos não foram amplamente discutidos com a comunidade, e inexiste um Programa de Educação Ambiental permanente. Inexiste também sistema público de tratamento de esgotamento sanitário, e os contratos assinados entre a Corsan e a Prefeitura Municipal não vêm sendo cumpridos e não há nada de concreto, nada que garanta, que isso aconteça no tempo previsto. No abastecimento público há dificuldade devido às intensas mudanças climáticas, aumento da população, atividades antrópicas, os rios serem de pequeno porte e há prognóstico de continuar a ocorrer estiagem com racionamentos. A população tem como ônus o custo social e ambiental pelo não planejamento, falta de ações e não cumprimento dos contratos. Quanto à transposição do Rio Cravo parece que será somente uma obra para remediar de forma muito precária o problema da escassez de água potável no município de Erechim. O COMPAM não vem atuando de forma eficiente, técnica e dentro da legislação municipal. Por vezes é alheio as questões de cunho ambiental e há visível falta de organização interna. Palavras-chave: Gestão Ambiental, Recursos Hídricos, Planos Ambientais.
\end{abstract}

\begin{abstract}
The objective of this work was to analyze the present status of the management of the water resources in the municipality of Erechim (RS) based on the management plans, statistical data, history and information gathered with the responsible managers by the legal institutions responsible for the public environmental policies of the municipality such as the Municipal Environmental Office (SMMA), the City Hall, Apuaê Inhandava Hydrographic Basin Committee (CBHAI), the Hydrographic Basin Committee of Passo Fundo (CBHPF), the Municipal Environment Protection Committee (COMPAM) and Corsan. The results of this study were based on the understanding of the municipal plans and with the field research it was observed that the municipality possesses all the physical, institutional and legal structures and all necessary elements for the management of the environment, however, these offices have little interaction and the actions for environmental education are made in an isolated form. As per the use of management instruments it was observed that the municipality, through the CBHAI, has created an Action Plan in Water Resources, the Placement of the Water Bodies in preponderant usage classes and has started a plan to charge for the use of the water. The municipality, through the Municipal Environmental Office (SMMA), already uses the Environmental License and also has created the Municipal Environmental Plans, however those plans were not thoroughly discussed with the community and a permanent Environmental Education Program is inexistent. Also there is not a public system for the treatment of sanitary waste and the contracts signed between Corsan and the City Hall are not being complied with and there is not anything concrete, nothing that guarantees that this will happen in due time. There are also difficulties in the public water supply due to the intense climate changes, increase of the population, human activities, and the rivers being of small size and there is also a forecast that there will be drought spells with water rationing in the future. The population carries the weight of the social and environmental costs for the lack of planning, lack of actions and the failure to comply with the contracts. It seems that the transposition of the Cravo will be only to remedy, in a very precarious way, the problem of potable water in the municipality of Erechim. COMPAM has not been acting in an efficient, technical way and according to the municipal laws. Sometimes it seems oblivious to environmental issues and there is a visible lack of internal organization.
\end{abstract}

Keywords: Environmental Management, Water Resources, Environmental Plans. 


\section{INTRODUÇÃO}

As ações do homem têm repercussões nas bacias hidrográficas se refletindo na quantidade e qualidade das águas. Os múltiplos usos das águas, atividades agrícolas e pecuárias, presença de cidades exercem grande pressão sobre os recursos naturais que compõem uma bacia hidrográfica como desmatamento, poluição e desertificação (CBHAI, 2010).

A gestão ambiental tem se configurado como uma das mais importantes atividades relacionadas a qualquer empreendimento, já que a implantação de um Sistema de Gestão Ambiental (SGA) estruturado e integrado à organização possibilita que os procedimentos relacionados às questões ambientais tornem-se eficazes (SIGA-RS /SEMA-RS, 2009).

O município de Erechim é um divisor de águas para duas bacias hidrográficas em termos de Estado do Rio Grande do Sul sendo que esta divisão ocorre na área urbana, onde para Norte, Leste e Sudeste as águas são drenadas em sentido a Bacia Hidrográfica Apuaê-Inhandava (U010) tendo como orientação hidrográfica no sentido Oeste/Leste e posteriormente para Norte em direção a calha do Rio Uruguai. A porção Oeste e Sudoeste do município apresentam como sentido de drenagem para a Bacia Hidrográfica do Rio Passo Fundo (U020), o qual tem com sentido de drenagem Oeste/Leste e posteriormente Norte, desaguando primeiramente na Barragem do Rio Passo Fundo e posteriormente no Rio Uruguai (PLANO DE MANEJO DA APA DOS RIOS LIGEIRINHO E LEÃOZINHO, p.44, 2011).

Erechim tem passado por períodos de estiagem $(2005,2009,2011$ e 2012) que hoje parecem ser cíclicos, exigindo dos gestores públicos planejamento e ações mais efetivas quanto aos recursos hídricos a fim de garantir a oferta de água em termos de qualidade e quantidade necessária ao abastecimento do município.

\section{METODOLOGIA}

Este trabalho técnico foi realizado através do Instituto Sócio Ambiental Vida Verde - ELOVERDE®. A pesquisa desenvolveu-se no município de Erechim/RS que se localiza ao norte do Rio Grande do Sul, na região do Alto Uruguai, com uma população de 96.087 habitantes (IBGE, 2010).

$\mathrm{Na}$ primeira parte deste estudo fez-se uma pesquisa teórica para fundamentar o conhecimento sobre o tema proposto - Gestão de Recursos
Hídricos e na segunda parte buscou-se conhecer e aprofundar a questão da Gestão de Recursos Hídricos do município de Erechim. Para tanto se pesquisou os planos ambientais do município, além de pesquisa de campo por meio de entrevistas semi-estruturadas a gestores das instituições que lidam diretamente com este tema como CBHAI, CBHPF, COMPAM, CORSAN e SMMA.

\section{RESULTADOS E DISCUSSÃO}

A Prefeitura através da Lei Municipal no 3.140/1999 criou o COMPAM órgão de caráter consultivo, deliberativo e de assessoramento. As secretarias da administração municipal devem tratar da questão ambiental e a Câmara Municipal é essencial no seu papel legislador e fiscalizador dos atos do Poder Público é importante também, as entidades privadas, órgãos técnicos estaduais e federais que possam conveniar-se com o município.

O Departamento de Meio Ambiente de Erechim iniciou suas atividades em agosto de 2001 e a partir de janeiro de 2002 passou a ser autônomo e dissociado da Vigilância Sanitária. Em 2003 através da Lei 3.647 foi criada a Secretaria Municipal de Meio Ambiente. Segundo o Art. 33 da Lei n. ${ }^{\circ} 4.420$, de 11 de fevereiro de 2009, que dispõe sobre a Estrutura Administrativa do Poder Executivo Municipal, cria os Cargos de Confiança e dá outras providências.

A prioridade para se utilizar o montante dos recursos previstos para 2013, que é de 9 milhões de reais é executar os Planos de Manejo do município (Plano Diretor de Arborização Urbana; Plano de Manejo do Parque Natural Municipal Longines Malinowski; Plano de Ações do Horto Municipal e Área Verde do Distrito Industrial; Plano de Manejo da APA do Rio Suzana e APA dos Rios Ligeirinho e Leãozinho além do Plano de Esgotamento Sanitário), que serão descritos abaixo.

\section{I Plano Ambiental Municipal de Erechim (2006 e 201I)}

Erechim possui histórico de desenvolvimento alicerçado em interesses específicos e isolados. Como conseqüência, criou-se um cenário preocupante em relação aos fatores ambientais revelado pelo avançado processo de fragmentação das áreas naturais, comprometimento dos recursos hídricos e ameaças à biodiversidade local e regional. O histórico recente do município bem como a atual condução das políticas públicas revela um prognóstico desfavorável e inaceitável na perspectiva da sustentabilidade do uso dos 


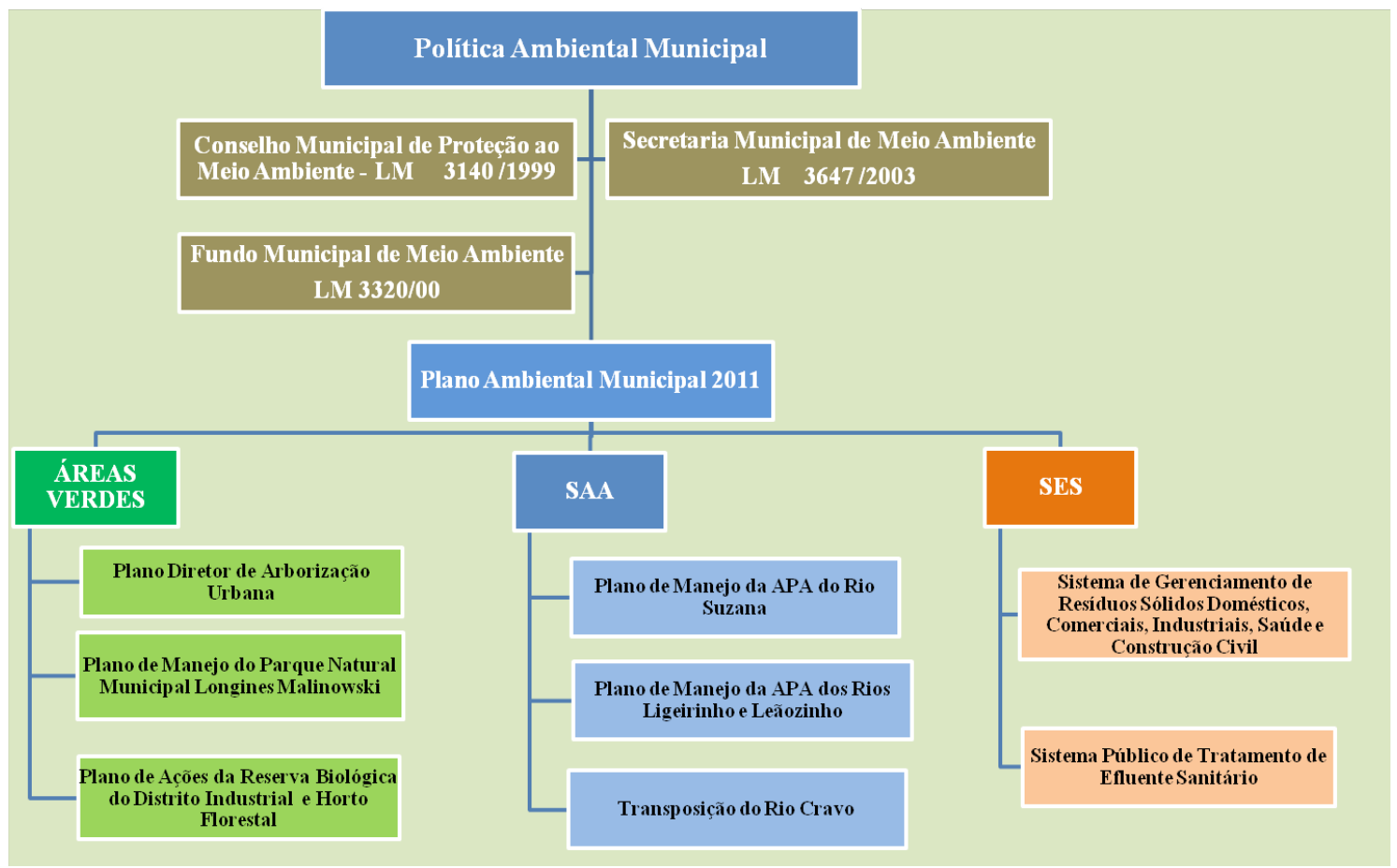

Figura 1- Organograma da Estrutura Organizacional para o Plano Ambiental Municipal com os Planos Ambientais de Áreas Verdes, Sistema de Abastecimento de Água e Sistema de Esgotamento Sanitário do Município de Erechim - RS.

Fonte: Criado pela autora com base nos planos municipais, 2012.

recursos naturais e da conservação da biodiversidade (PAM, 2006, p. 82).

Em questionamento a técnico da SMMA para verificar a efetividade das propostas previstas no PAM 2006, com relação à destinação final de embalagens de agrotóxicos foram feitas campanhas de sensibilização para que os agricultores devolvam as embalagens após o uso, já quanto a destinação final dos resíduos de suinocultura há um cruzamento das informações através da fiscalização e licenciamento. Na questão de recuperação e preservação de matas ciliares não há projeto permanente, somente atividades pontuais desenvolvidas por algumas entidades. Os projetos previstos no PAM 2006 não foram em sua totalidade cumpridos. Não há informação específica sobre o tratamento e destinação final dos dejetos da suinocultura. Citam-se as propostas previstas no PAM 2011: Programa Cidadão Consciente, Execução do Plano de Manejo do Parque Natural Municipal Longines Malinowski, Plano Diretor de Arborização Urbana, Plano de Saneamento, Transposição do Rio Cravo e Implantação das Áreas de Proteção Ambiental (APA) do Rio Ligeirinho Leãozinho e APA do Rio Suzana, pretende- se colocar em prática as propostas contidas nestes planos, a partir de 2013.

\subsection{Gestão de Áreas Verdes A - Plano Diretor de Arborização Urbana}

A Gestão de Áreas Verdes prevê a execução do Plano Diretor de Arborização Urbana de Erechim- PDAU e Plano de Manejo do Parque Natural Municipal Longines Malinowski - PNMLM previstos no PAM, 2011, assim como o Plano de Ações para a Reserva Biológica do Distrito Industrial e Horto Florestal Municipal de Erechim.

A Reserva Biológica do Distrito Industrial está situada na zona urbana do município de Erechim/RS, próximo a BR 153, no Bairro Distrito Industrial. Ocupa uma área de 10,28 ha, corresponde a um fragmento típico de Floresta Ombrófila Mista, com uma área de Vegetação Implantada (Pinus sp.).

O Horto Florestal localizado na Bacia Hidrográfica do Rio Cravo é definido como um fragmento de vegetação arbórea com área total de 70,99 ha inserido em uma matriz agrícola. Esta matriz caracteriza-se por pequenas propriedades que desenvolvem a agricultura familiar.

A área urbana do município de Erechim está dividida em 32 bairros, apresentando 414 áreas verdes públicas que se dividem em 377 canteiros centrais, 36 praças e um parque, o Parque Natural Municipal Longines Malinowski (PDAU, 2011 p.18).

As principais propostas do PDAU são a Manutenção da Remoção de Indivíduos, Controle Fitossanitário, Replantio, Tutoramento, Área Livre e Poda, o Monitoramento das árvores exis- 


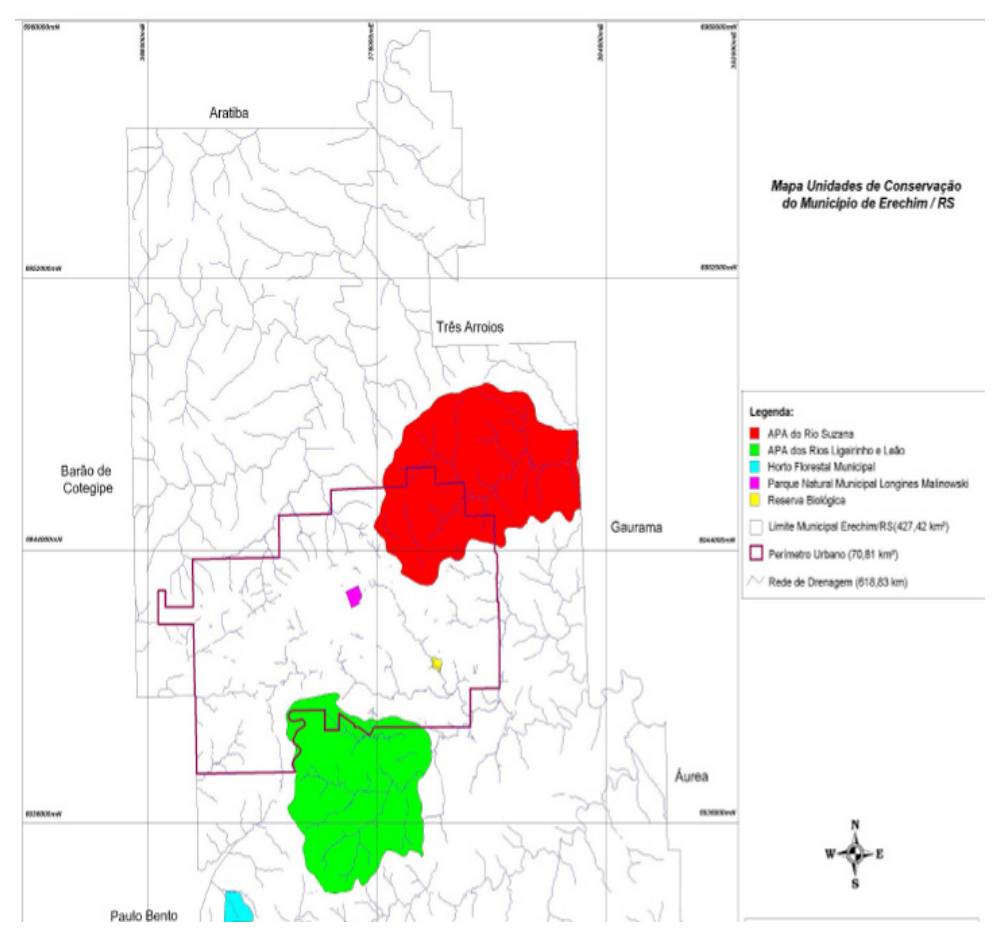

Figura 2- Mapa das Unidades de Conservação do município de Erechim.

Fonte: Plano de Manejo do Parque Natural Municipal Longines Malinowski, 2011.

tentes e das mudas plantadas nas vias públicas de Erechim, e a Educação Ambiental que contém 3 sub programas: Sub-Programa de Informação Coletiva, Sub-Programa de Educação Formal e Sub-Programa de Educação Informal e Participação Comunitária.

No PDAU não estão definidas quais as espécies nativas (5) que serão plantadas por quadra, sugere-se que haja consulta a técnicos da área (biólogos, tecnólogos, engenheiros) que definam essas espécies.

\section{B - Plano de Manejo do Parque Natural Municipal Longines Malinowski}

O Parque Natural Municipal Longines Malinowski (PNMLM), situado na área central da cidade de Erechim é categorizado como uma Unidade de Conservação (UC) de Proteção Integral (Sistema Nacional de Unidades de Conservação - SNUC - Capítulo III, Artigo $7^{\circ}, \S 1^{\circ}$ ) tem por objetivo preservar a natureza, sendo admitido apenas o uso indireto dos seus recursos naturais, com exceção dos casos previstos em lei.

Erechim é uma das poucas cidades brasileiras a ter um parque situado dentro do perímetro urbano. No PNMLM há a presença de inúmeras nascentes, uma delas a do Lajeado Banhado é contribuinte do Rio Tigre.

Para que a população de modo geral (e não somente as escolas) possam usufruir do parque são necessárias diversas ações por parte da SMMA: divulgação nos meios de comunicação sobre os atrativos do parque, maior segurança nos arredores do parque, palestras e atividades de sensibilização, mostrar a realidade do parque através de campanhas educativas principalmente na questão dos resíduos sólidos depositados irregularmente.

Os principais programas previstos no Plano de Manejo do PNMLM são: Programa de Proteção/Manejo, Programa de Pesquisa, Programa de Monitoramento Ambiental, Programa de Uso Público, Programa de Educação Ambiental e Comunicação e Programa de Proteção

\subsection{Plano de Manejo da APA do Rio Suzana}

A APA do Rio Suzana foi criada em 4 de janeiro de 1994, Lei Municipal no 2595 com o objetivo de assegurar a preservação, a melhoria e a recuperação da qualidade ambiental da região dos mananciais e garantir a potabilidade da água coletada para o consumo da população dos municípios de Gaurama e Viadutos. O Rio Suzana é o maior tributário da Área de Proteção Ambiental e fornece água para os demais córregos. (PLANO DE MANEJO DA APA DO RIO SUZANA, 2011). Os principais programas do Plano de Manejo da APA do rio Suzana são: Programa de 


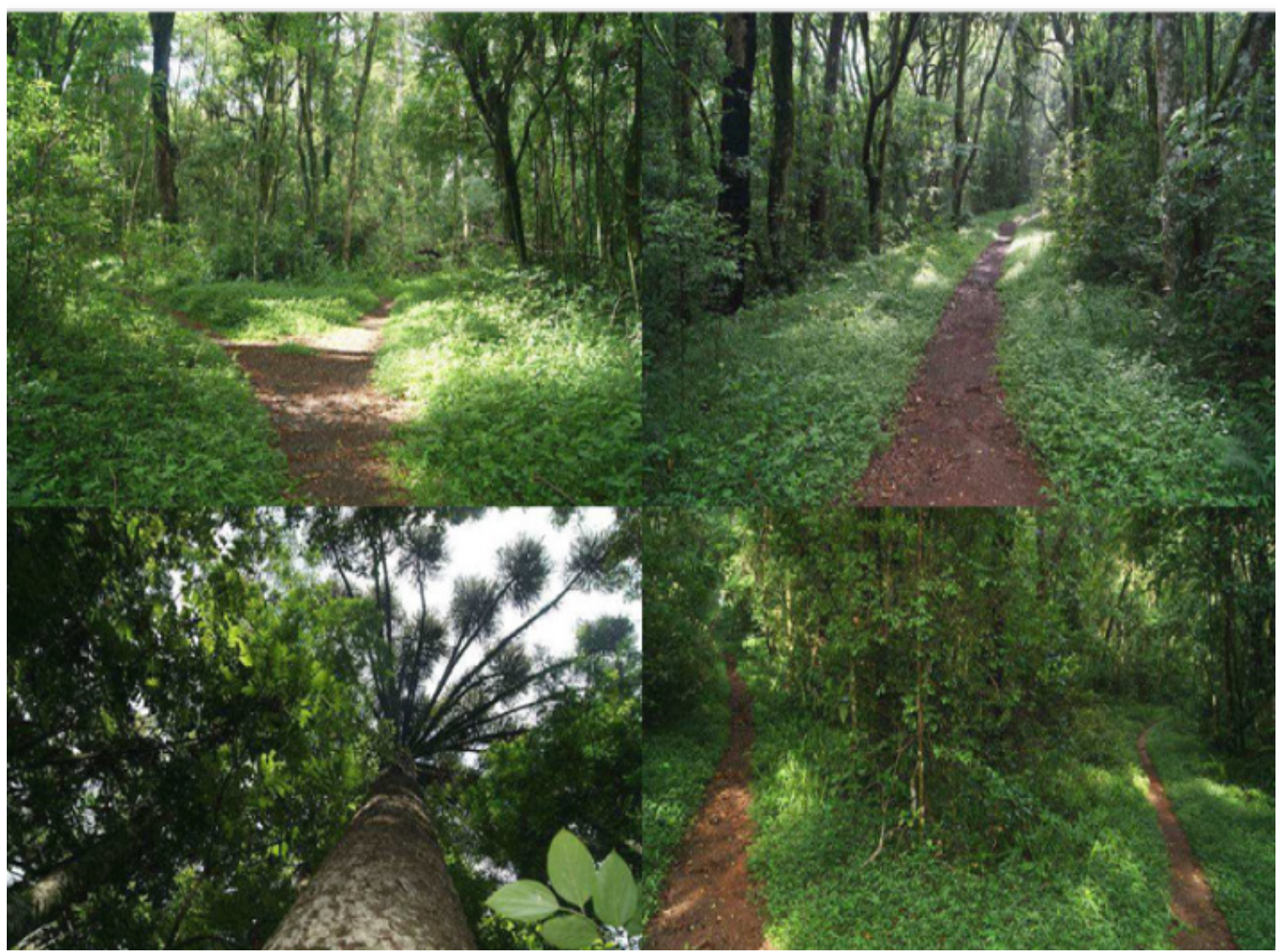

Figura 3- Beleza Natural do PNMLM.

Fonte: Plano de Manejo do PNMLM, 2011.

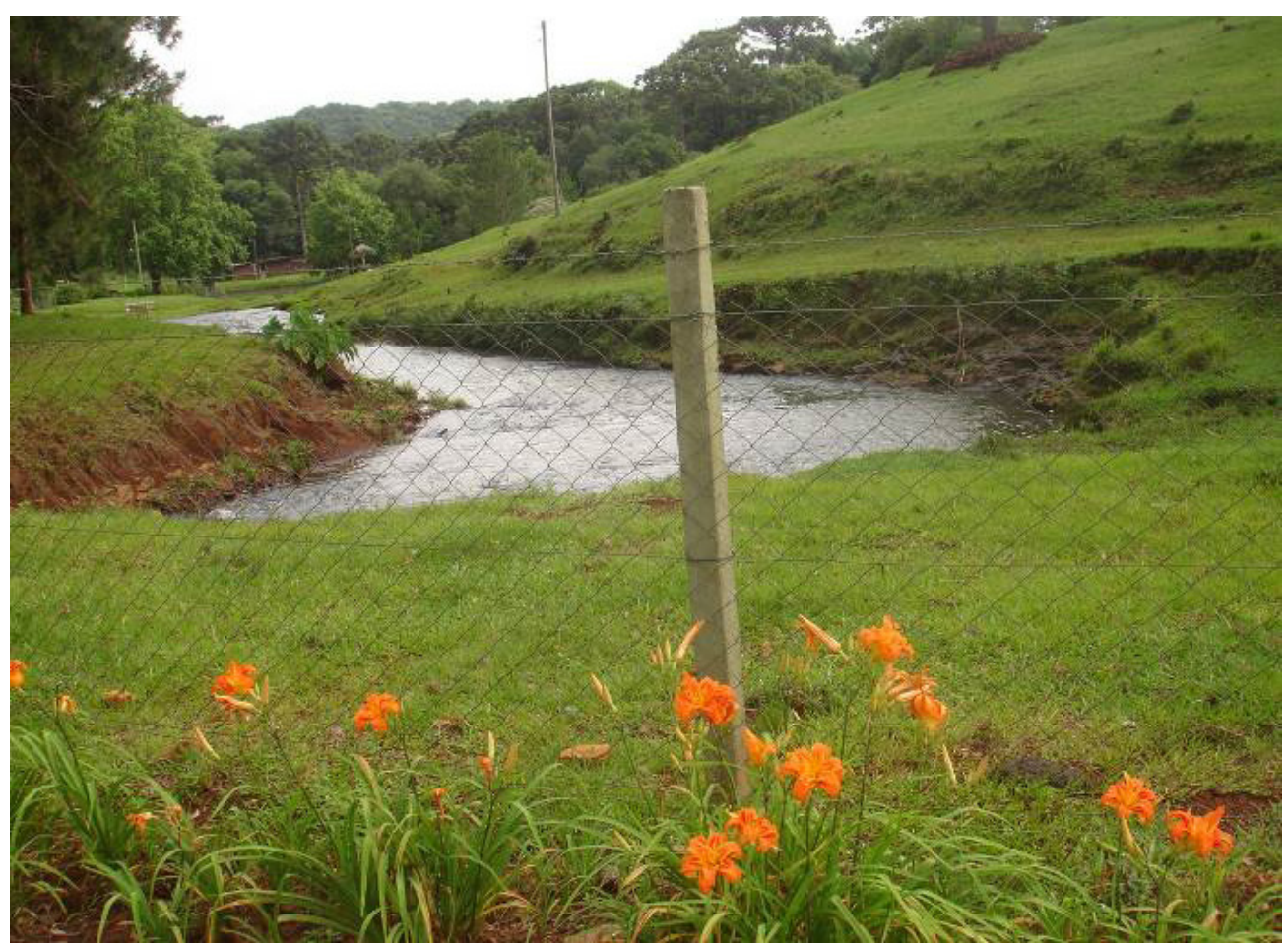

Figura 4- Imagem do Rio Suzana.

Fonte: Eloverde, 2010 


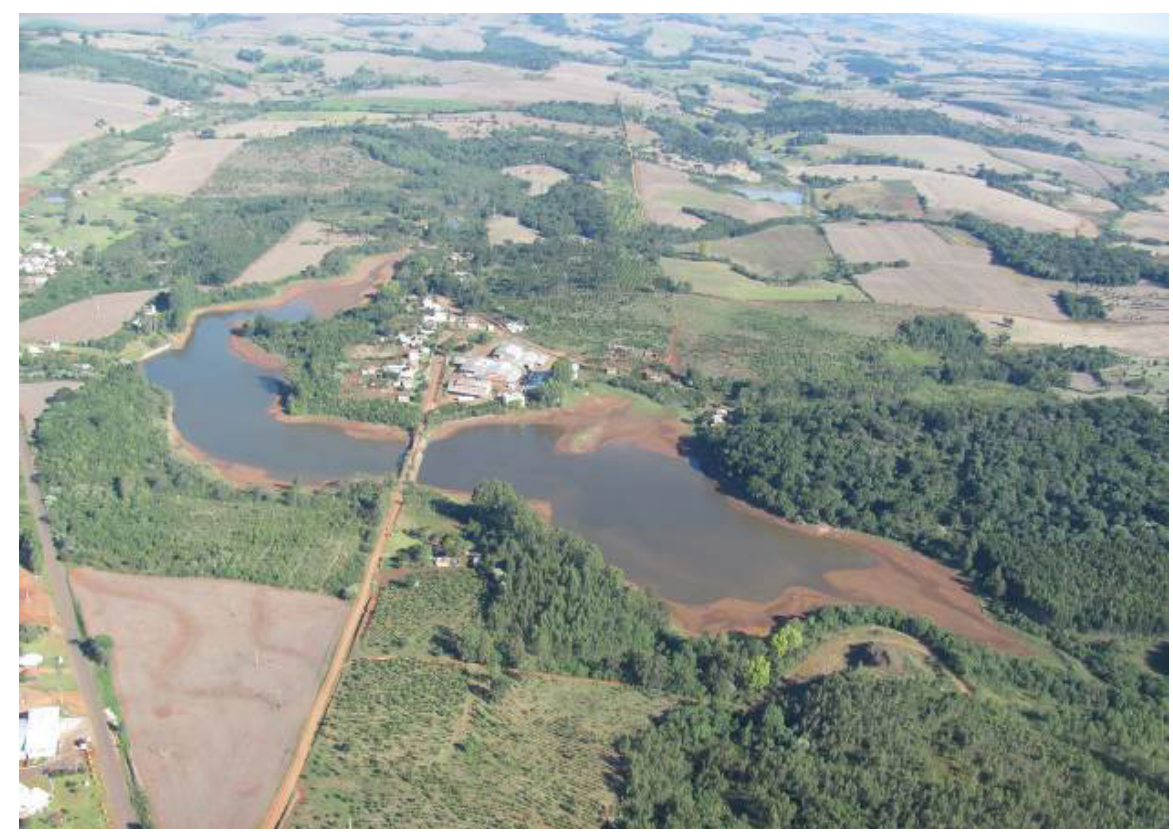

Figura 5- Imagem Aérea da Barragem de Abastecimento Público de Erechim.

Fonte: Eloverde, 2012.

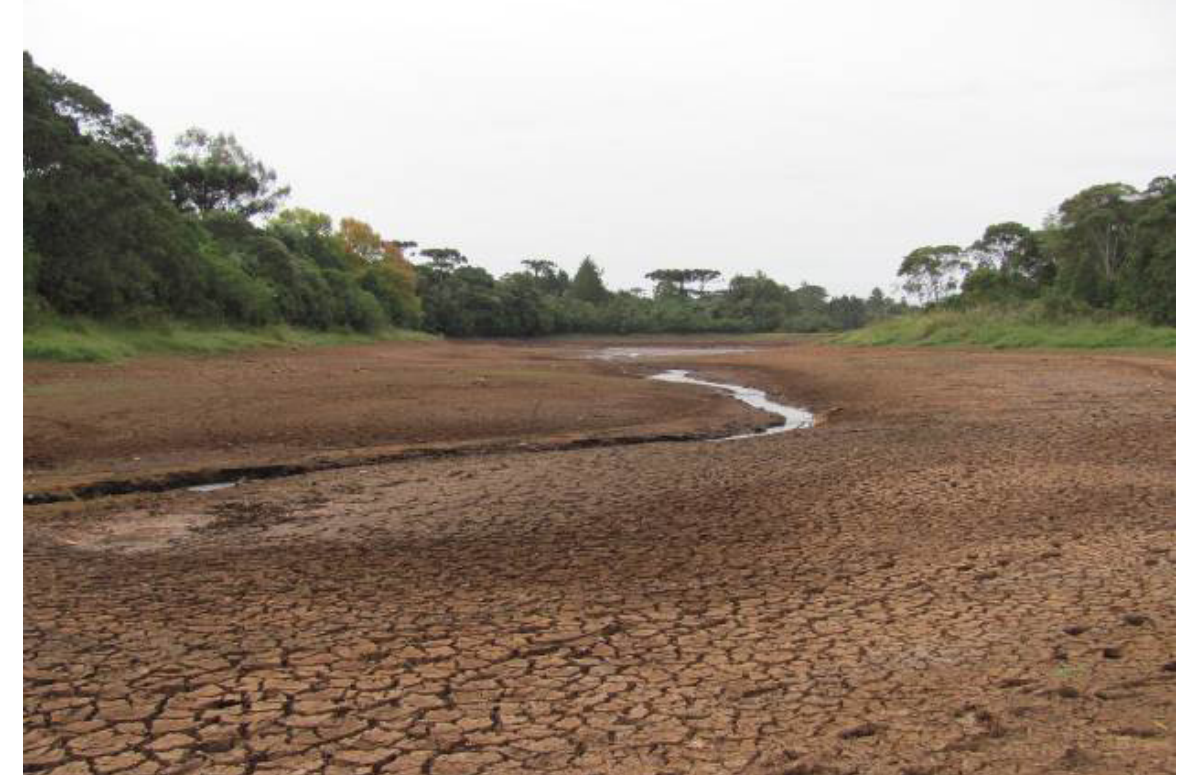

Figura 6 - Seca em Erechim.

Fonte: Eloverde, 2012.

Proteção/Manejo, Programa de Pesquisa e Monitoramento, Programa de Visitação e Ecoturismo, Programa de Educação e Comunicação Ambiental e Programa de Restauração de APPs em Conflito.

Não há por parte da SMMA o controle ou monitoramento da vazão da APA do rio Suzana, há somente estudos realizados pela universidade, alega-se que o responsável por estas questões seja a Corsan. Segundo entrevista realizada com técnico da SMMA, a mesma não conta com estrutura e equipe que possa fazer esse trabalho de monitoramento de vazão.
O Sistema Público de Abastecimento de Água segue o padrão de drenagem dendrítico (arborescente) que se assemelha a tronco e galhos de uma árvore, de densidade média, estando mais ligados à morfologia do terreno do que a sua estrutura geológica (ANDERSON e VERSTAPEN, 1982; CHRISTOFOLETTI, 1980). As maiores densidades de drenagem estão nas microbacias Cravo $(14,76 \mathrm{~m} / \mathrm{ha})$, Suzana $(14,42 \mathrm{~m} / \mathrm{ha})$ e Tigre $(13,01 \mathrm{~m} / \mathrm{ha})$, seguidas pela Henrique $(12,84 \mathrm{~m} /$ ha), Dourado (12,64 m/ha) e Campo (12,53 m/ ha) (PLANO AMBIENTAL MUNICIPAL, 2011). 
A Corsan é a empresa responsável pela captação, tratamento e distribuição da água no município de Erechim. Os Rios Ligeirinho e Leãozinho, tributários do Rio Tigre são os responsáveis pelo abastecimento do reservatório da Corsan, com vazão de $250 \mathrm{~L} / \mathrm{s}$ e 40 $\mathrm{L} / \mathrm{s}$, o reservatório de acumulação da barragem tem capacidade de $790.000 \mathrm{~m}^{3}$ Em épocas de estiagem, a Corsan capta água do Rio Campo (captação média de 80 L/s) (PAM, 2011 p.220).

Quanto à reservação de água o volume total armazenado é de $7.200 \mathrm{~m}^{3}$ que segundo normas da ABNT está incompatível para os 92.614 habitantes urbanos atualmente abastecidos que necessitariam de um volume mínimo de 8.700 $\mathrm{m}^{3}$, portanto um déficit de $1.500 \mathrm{~m}^{3}$ no volume de reservação que corresponde a um índice de $83 \%$ (SES, 2009). Para o ano de 2012 a informação não pode ser obtida.

O sistema de abastecimento de água da cidade de Erechim conta com 8 centros de reservação.O índice de perdas na distribuição no ano de 2006 foi de 39,4\% e em 2007 foi 40,1\%. O índice de perdas é elevado e poderia ser melhor gerenciado principalmente se houvessem mais investimentos em melhoria de infraestrutura pela Corsan.

Devido ao contrato assinado pela Prefeitura Municipal de Erechim e a Corsan ter um prazo muito longo para o cumprimento e sempre ter sido prorrogado, o meio ambiente foi se degradando e a população teve que pagar pelo ônus da falta de investimentos e não planejamento, gestão ineficiente e até omissa, além do constrangimento e sentimento de revolta pelos constantes racionamentos de água. Os não investimentos para o tratamento de esgoto trouxeram como conseqüências a poluição do corpo hídrico e doenças para a população pela falta de saneamento básico.

\section{4 Plano de Manejo da APA dos Rios Ligeirinho e Leãozinho}

A missão da APA dos Rios Ligeirinho e Leãozinho é a manutenção da qualidade e da quantidade de água para o abastecimento público do município de Erechim, bem como a conservação da biodiversidade local.

Os principais programas do Plano de Manejo da APA dos Rios Ligeirinho e Leãozinho são: Programa de Proteção/Manejo, Programa de Pesquisa e Monitoramento, Programa de Visitação e Ecoturismo, Programa de Educação e Comunicação Ambiental, Programa de Restauração de APPs em Conflito.

Ainda está para se tornar oficial à criação da APA dos Rios Ligeirinho e Leãozinho, depois se pensará em arranjos institucionais. Há que atentar que os proprietários são responsáveis também por estas áreas e devem se envolver em programas e projetos de cunho ambiental. Nota-se mais uma vez que o município delega funções que seriam pertinentes a SMMA para outras instituições e para os moradores do entorno da APA.

Quanto a articulação com o CBHAI a parceria já existe e a SMMA tem acento no comitê. As instituições trocam informações e buscam somar esforços para solucionar os problemas e executar o Plano de Ações, elaborado pelo comitê.

Falta no município de Erechim ser implementado um projeto contínuo e permanente de Educação Ambiental para se concretizar o exer-

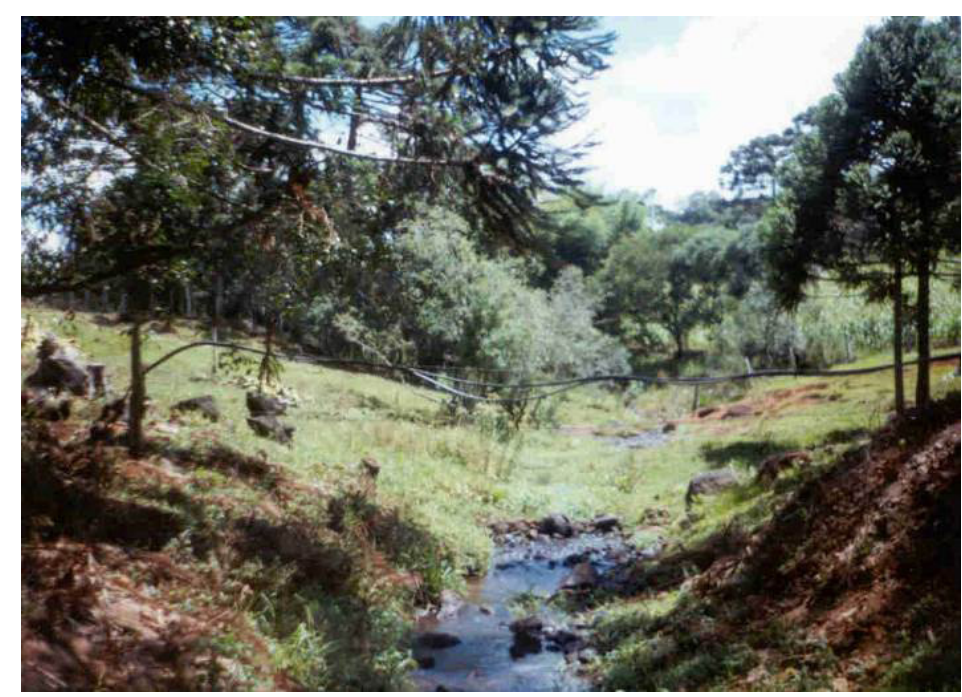

Figura 7 - Resquícios da vegetação ciliar- Rio Leãozinho.

Fonte: Zanella, M, 2002. 


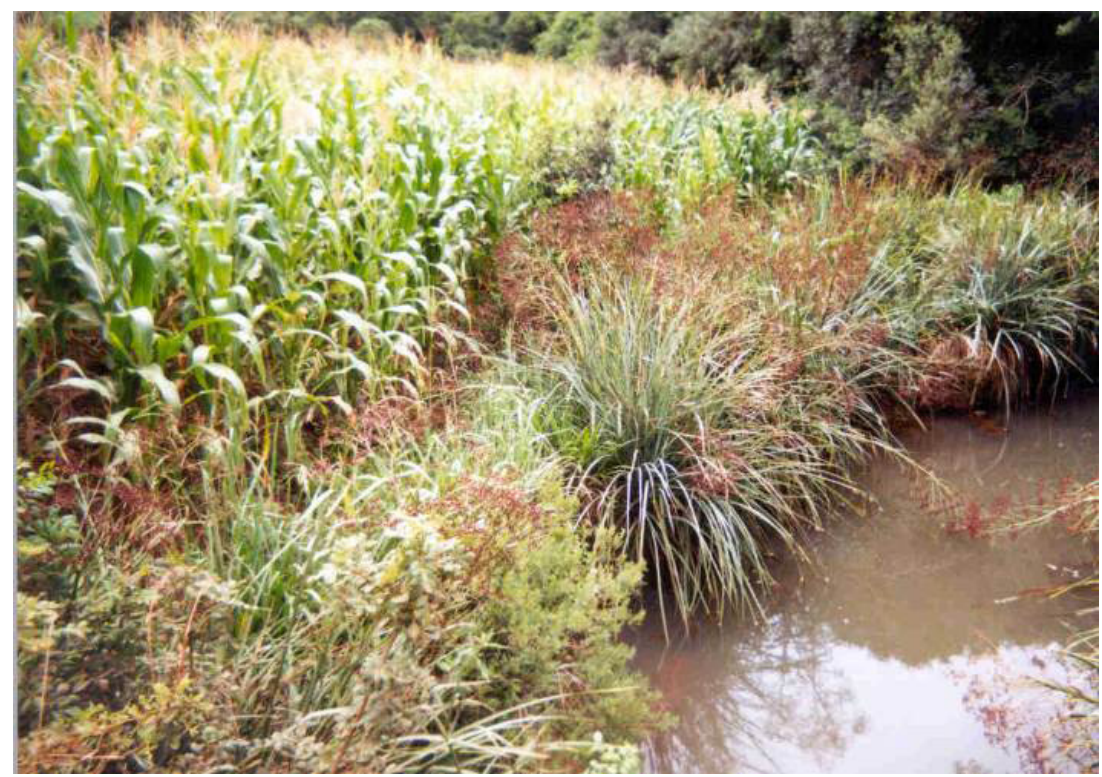

Figura 8- Plantio de milho as margens do Rio Ligeirinho.

Fonte: Eloverde, 2010.

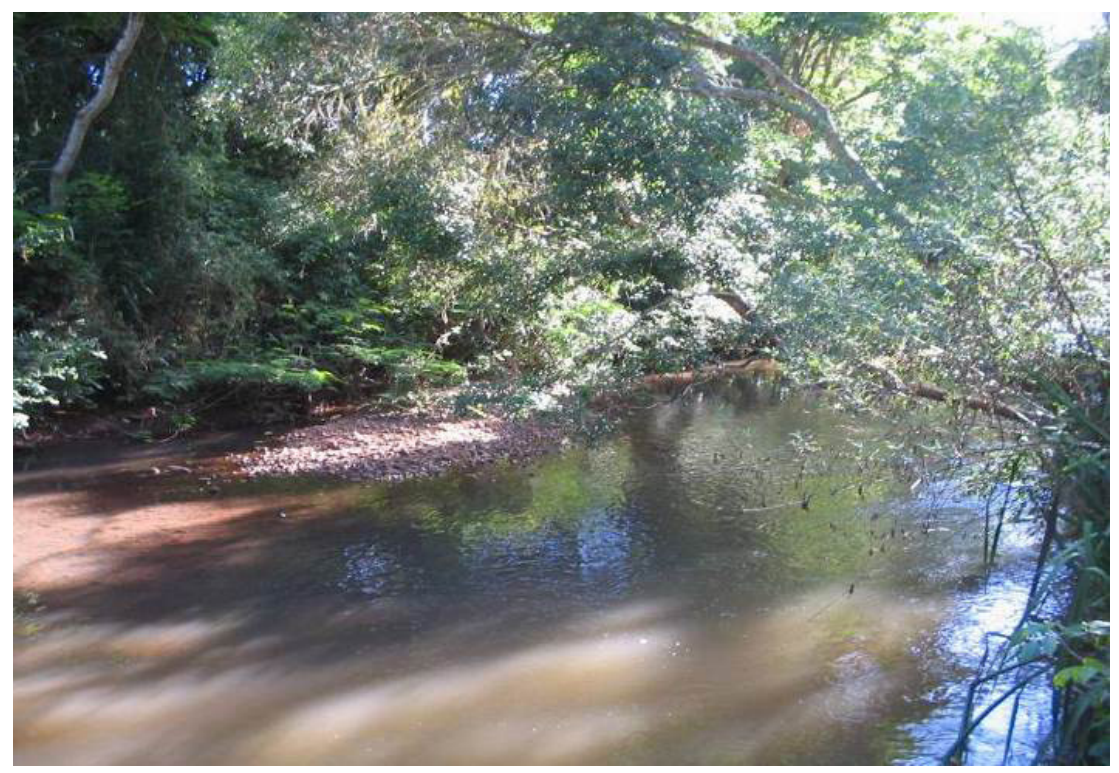

Figura 9- Rio Campo (Outorga da Corsan).

Fonte: Eloverde, 2010.

cício da cidadania e buscar ações transformadoras e eficientes e melhorar a qualidade da vida da coletividade.

\section{5 Transposição do Rio Cravo}

$\mathrm{Na}$ sub-bacia do Rio Cravo foram identificados 5 pontos passíveis de captação de água bruta. Após estudos de detalhamento de cada um deles, optou-se pelo denominado "Local 4", por tratar-se do melhor local sob o ponto de vista de conformação topográfica para a construção do novo barramento, tanto sob o ponto de vista de geotecnia, bem como sob o ponto de vista de entrada imediata em operação, a partir de captação direta no curso de água (PAM, 2011).

A partir deste ponto, o projeto prevê a implantação de um sistema adutor com 16 quilômetros de comprimento até o local de descarregamento no lago da barragem do Ligeirinho.

Nota-se a falta de visão por parte da concessionária, pois o investimento para a transposição é alto e a vida útil estimada é muito curta ( + ou -25 a 30 anos) além do que será utilizada somente em épocas de estiagem e é baseado no crescimento vegetativo da população. Parece que a transposição 


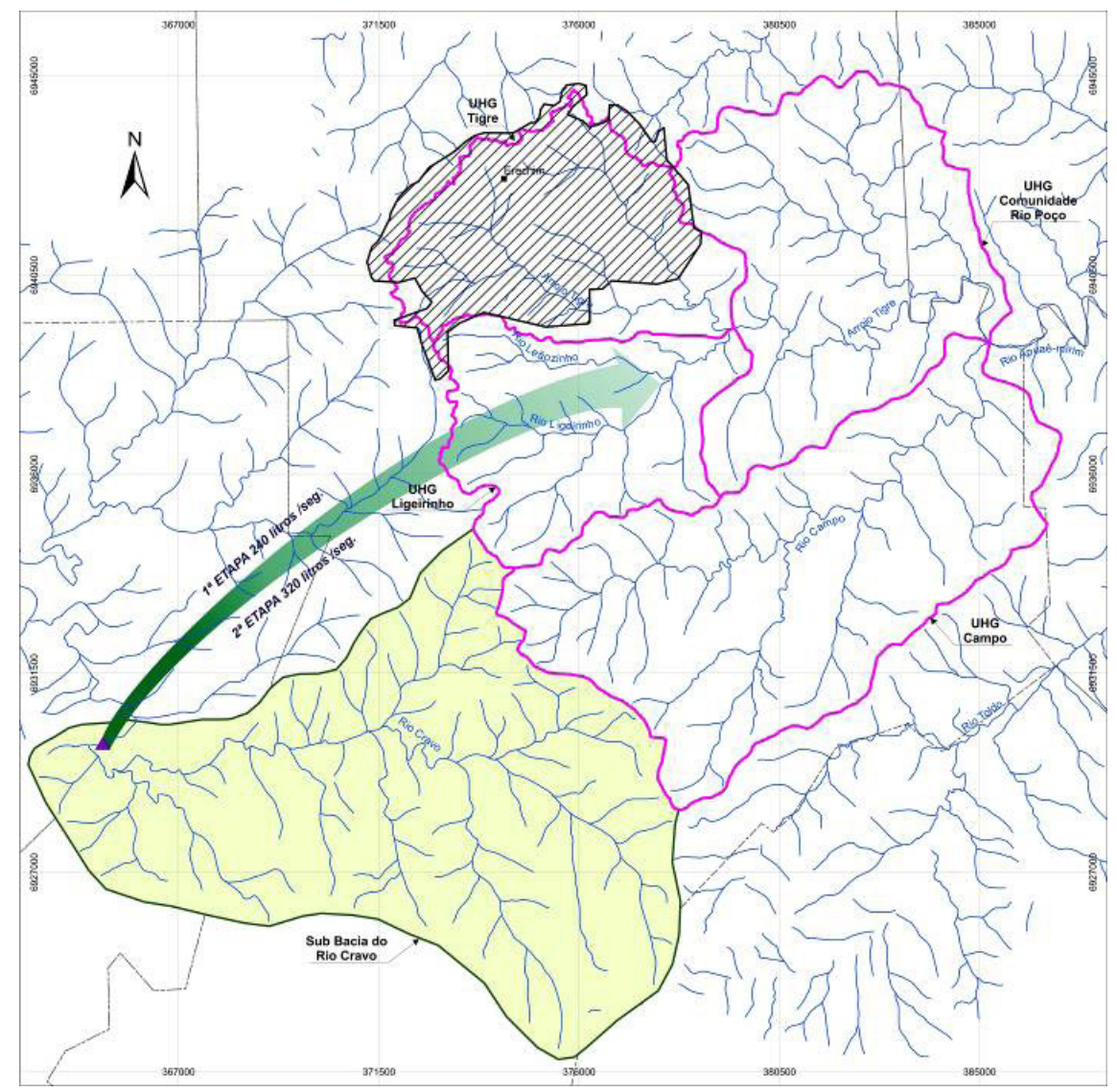

Figura 10 - Transposição da Sub-bacia do Rio Cravo para a UHG Ligeirinho.

Fonte: CBHAI, 2009.

será somente uma obra para remediar de forma muito precária o problema da escassez de água potável no município de Erechim.

\subsection{Comitê de Bacia Hidrográfica Apuaê Inhandava}

O Comitê de Bacia Hidrográfica Apuaê Inhandava (CBHAI) em 2009, através de contrato firmado com a ACL Assessoria e Consultoria Ltda e a Secretaria Estadual de Meio Ambiente realizou estudo para o Plano de Ações em Recursos Hídricos das Sub-Bacias do Arroio Tigre e Rio Campo, essas sub-bacias formam a área de manancial e captação para abastecimento público.

Para caracterização do cenário, a área foi dividida em 4 Unidades Hidrográficas Gerenciais (UHG): (UHG Tigre, UHG Ligeirinho, UHG Comunidade Rio Poço e UHG Campo), para cada uma foram realizados estudos de diagnóstico, prognóstico, cenário de enquadramento dos cursos de água em classes de uso e conservação e plano de ações.
A elaboração do Plano de Ações em Recursos Hídricos das Sub-Bacias do Arroio Tigre e Rio Campo desenvolveu-se em três etapas: $\mathrm{A}$ - Diagnóstico, $\mathrm{B}$ - Enquadramento e $\mathrm{C}$ - Plano de Ações. $\mathrm{O}$ processo de enquadramento dos cursos de água em classes de uso e conservação foi desenvolvido em três fases que evoluíram desde a realização de consultas públicas, uma em cada UHG, a coleta das manifestações quanto aos usos futuros desejados até apresentação, discussão e aprovação do enquadramento pela plenária do Comitê. Ficou estabelecido que a UHG Tigre é classe 3; UHG Rio Poço, Ligeirinho e Campo classe 1, sendo que ao longo do rio Tigre é classe 2 .

Em entrevista ao presidente do CBHAI notou-se que o mesmo busca recursos para viabilizar as ações prioritárias elencadas no Plano de Ações em Recursos Hídricos das Sub-Bacias do Arroio Tigre e Rio Campo. O CBHAI está propondo projeto único no valor de $\mathrm{R} \$ 160.000$, 00 anual, por 2 anos, para atuar em Programas de Educação Ambiental, Recomposição da Mata 


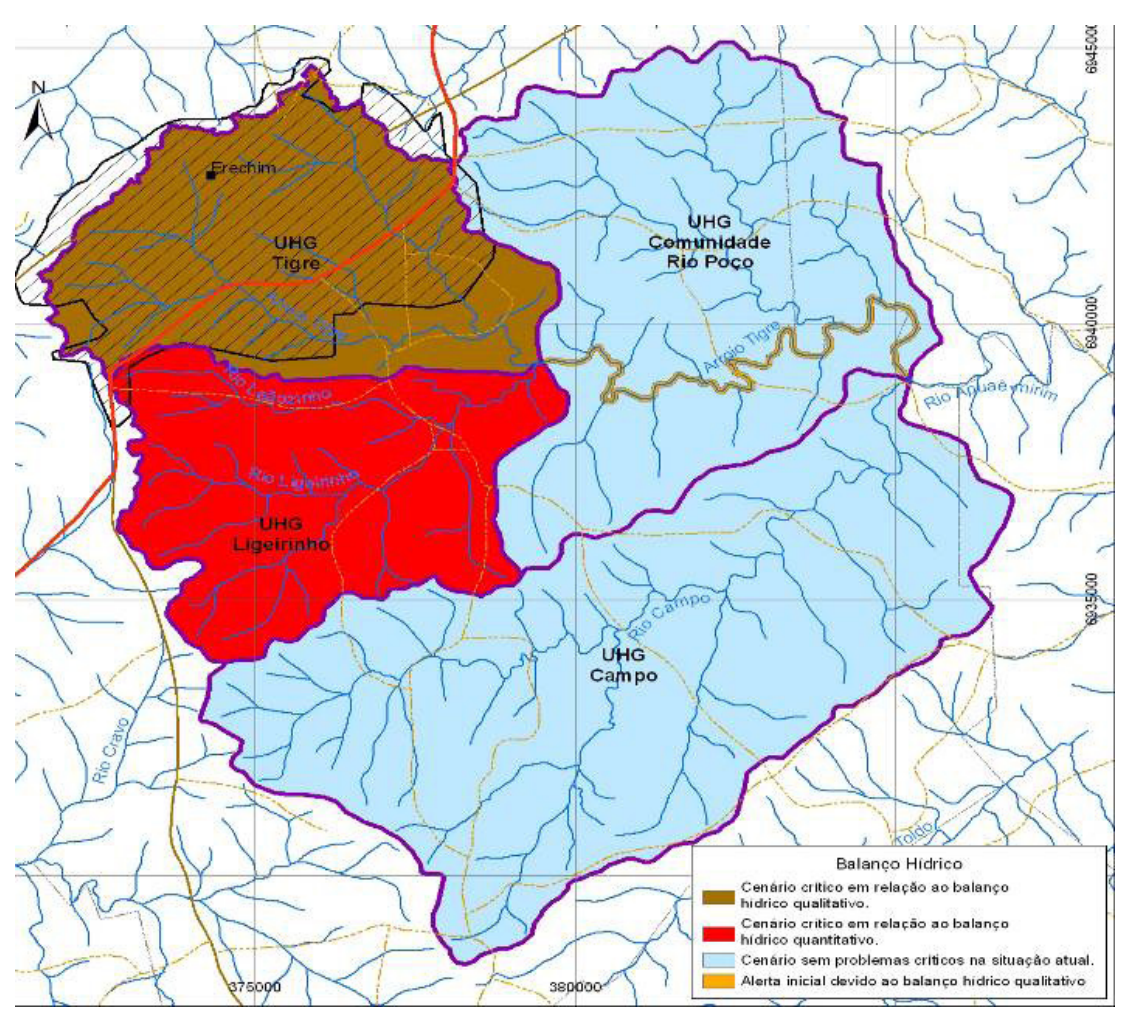

Figura 11- Enquadramento dos corpos hídricos do Plano de Ações em Recursos Hídricos das Sub-Bacias do Arroio Tigre e Rio Campo.

Fonte: CBHAI, 2009.

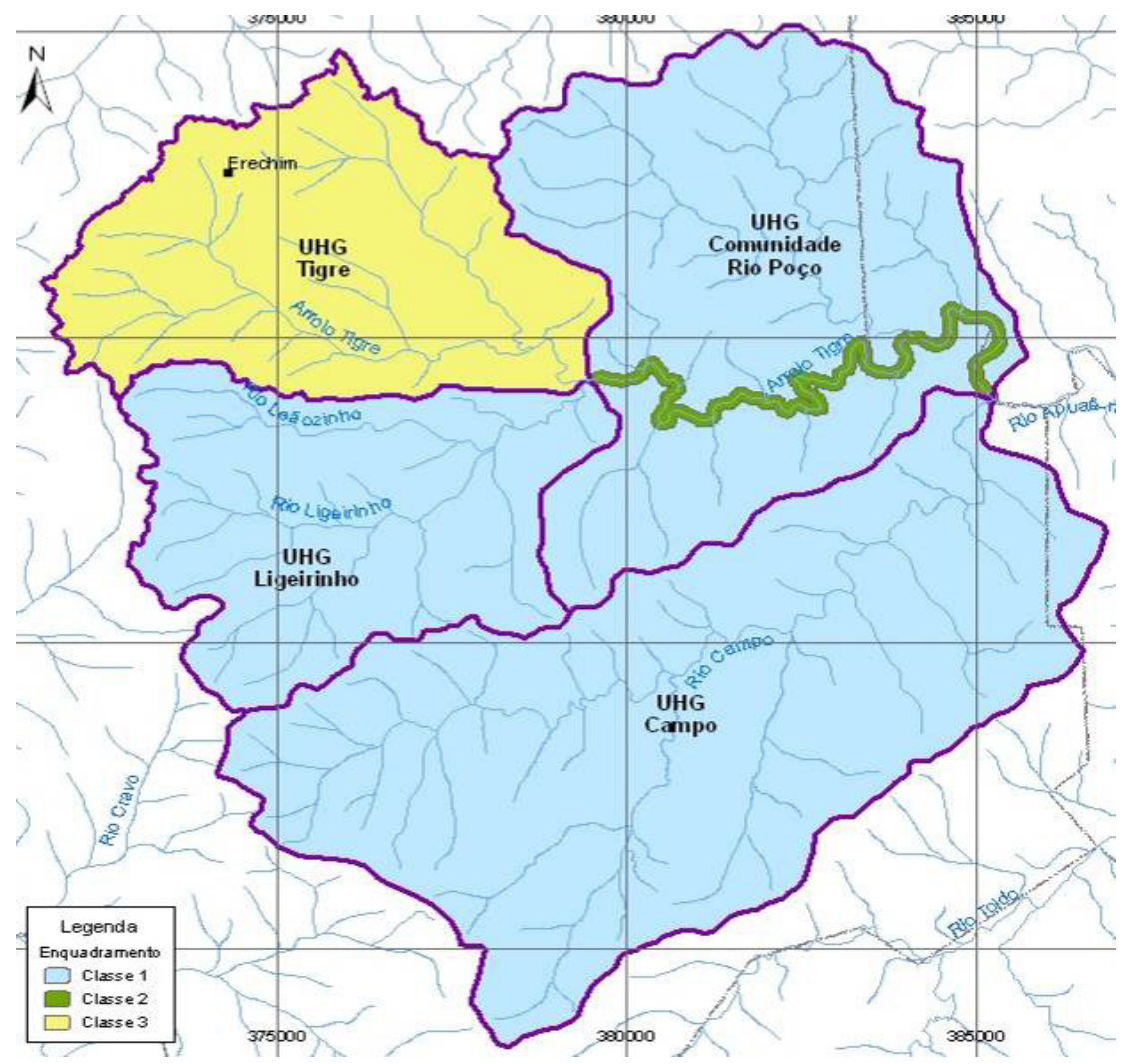

Figura 12- Síntese do Balanço Hídrico.

Fonte: CBHAI, 2009. 
Ciliar e Delimitação de Áreas de Proteção dos Recursos Hídricos -APP, Rede de Monitoramento da Qualidade das Águas e Estudo de Pagamento por Serviços Ambientais. As entidades executoras serão ELOVERDE, URI e o SUTRAF-AU com financiamento do Fundo Estadual de Recursos Hídricos (FRH).

Quanto à cobrança da água, o CBHAI vai colocar em prática a partir do momento em que for criada uma Agência de Região Hidrográfica conforme determina a legislação.

O estudo realizado pelo CBHAI demonstra a escassez de recursos hídricos disponíveis nos mananciais de abastecimento público do município de Erechim (Rios Ligeirinho e Leãozinho) cuja área deveria ser considerada estratégica na gestão pública.

\section{7. Sistema Público de Tratamento de Efluente Sanitário}

Segundo dados do Plano Ambiental Municipal (2011) e do Plano de Saneamento (2009) constam os seguintes estudos: Transposição do Rio Cravo, Sistema de Gerenciamento de Resíduos Sólidos Domésticos, Comerciais, Industriais, Saúde e Construção Civil e Sistema Público de Tratamento de Efluente Sanitário.

\section{A- Sistema de Gerenciamento de Resíduos Sólidos}

Quanto à destinação final dos resíduos sólidos urbanos existem algumas empresas privadas que realizam a triagem de resíduos sólidos e hoje já existem 6 associações de recicladores que atualmente realizam a triagem dos resíduos secos domésticos que através de parceria estabelecida com a Prefeitura Municipal recebem esses materiais por doação (PAM, 2006, p.70).

No ano de 2008, o lixo domiciliar que até então era depositado em "aterro controlado" nas proximidades do Parque Industrial, passou a ser destinado ao Aterro Sanitário que atualmente recebe a produção de lixo doméstico do município de Erechim que em média é de 55 toneladas/dia, segundo a SMMA (PAM, 2011 p. 217).

Uma parceria que merece ser mencionada é do Ministério Público Estadual, VEC (Vara das Execuções Criminais) do Fórum Comarca de Erechim e ELOVERDE que juntos executaram o Projeto Revitalização dos Rios de Erechim, num trabalho que buscou iniciar o processo de revitalização dos rios através do mapeamento de cenários; educação ambiental preventiva da comunidade do entorno dos rios e sociedade civil e limpeza física dos Rios Tigre, Suzana e Dourado de Erechim.
O projeto mostrou a realidade local do município de Erechim e pela inovação da metodologia utilizada durante os trabalhos foi premiado pelo Ministério do Meio Ambiente / Secretaria de Recursos Hídricos e Ambiente Urbano, em 2010 - Práticas Inovadoras em Revitalização de Bacias Hidrográficas - Tema: Educação Ambiental - $2^{\circ}$ lugar Categoria Ong's e em 2012 recebeu o primeiro lugar no Prêmio ANA (Agência Nacional das Águas), na categoria Ong's. Esta foi a ação de maior impacto e visibilidade gerando como resultado a redução de $60 \%$ dos resíduos encontrados nos rios (ELOVERDE, 2012).

\section{B-Sistema Público de Tratamento de Efluente Sanitário}

O Plano de Saneamento Municipal de Erechim (AMPLA, 2009), cita três alternativas para a implantação do SES (Sistema de Esgotamento Sanitário) de Erechim, onde a Alternativa 3, indica que o sistema ficará constituído por quatro grandes interceptores de vazão limitada - os Interceptores, SE1, SE2, SE3 e SE4-, um trecho de interceptor comum aos mesmos, a Estação Elevatória Final e sua Linha de Recalque e a Estação de Tratamento de Esgoto Sudeste, esta alternativa é apresentada como a melhor proposta, levando em conta o custo/beneficio (PAM, 2011 p.219).

Foram definidas duas ETE's com a posição de uma no terreno à margem direita do Rio Tigre, e a outra à margem direita da BR-153. O efluente líquido tratado terá como corpo receptor o Rio Tigre.

Foi elaborado um estudo técnico e econômico que levou em consideração o custo de implantação e de operação $\left(\mathrm{R} \$ / \mathrm{m}^{3}\right)$. A solução para o tratamento mais economicamente viável foi a do tipo Lagoa anaeróbia + Aerada facultativa + Lagoa de decantação, pois teriam o menor custo de implantação e operação (PAM, 2011 p.219).

O Sistema de Esgotamento e Tratamento de Esgoto proposto compreende a divisão da cidade em várias bacias e sub-bacias, com o esgoto sanitário e a água de chuva encaminhados conjuntamente para tratamento em duas ETE's. O modelo de ETE proposto para o SES de Erechim é a utilização em série dos processos Anaeróbio e Aeróbio. As unidades que compõem a ETE proposta podem ser distribuídas em quatro conjuntos, que de forma integrada constituirão um bloco de edificações funcionalmente eficiente: Primeiro Conjunto: Etapa de Tratamento Preliminar; Segundo Conjunto: Etapa de Tratamento Primário - Anaeróbio; Terceiro Conjunto: Etapa de Tratamento Secundário - Aeróbio e Quarto 


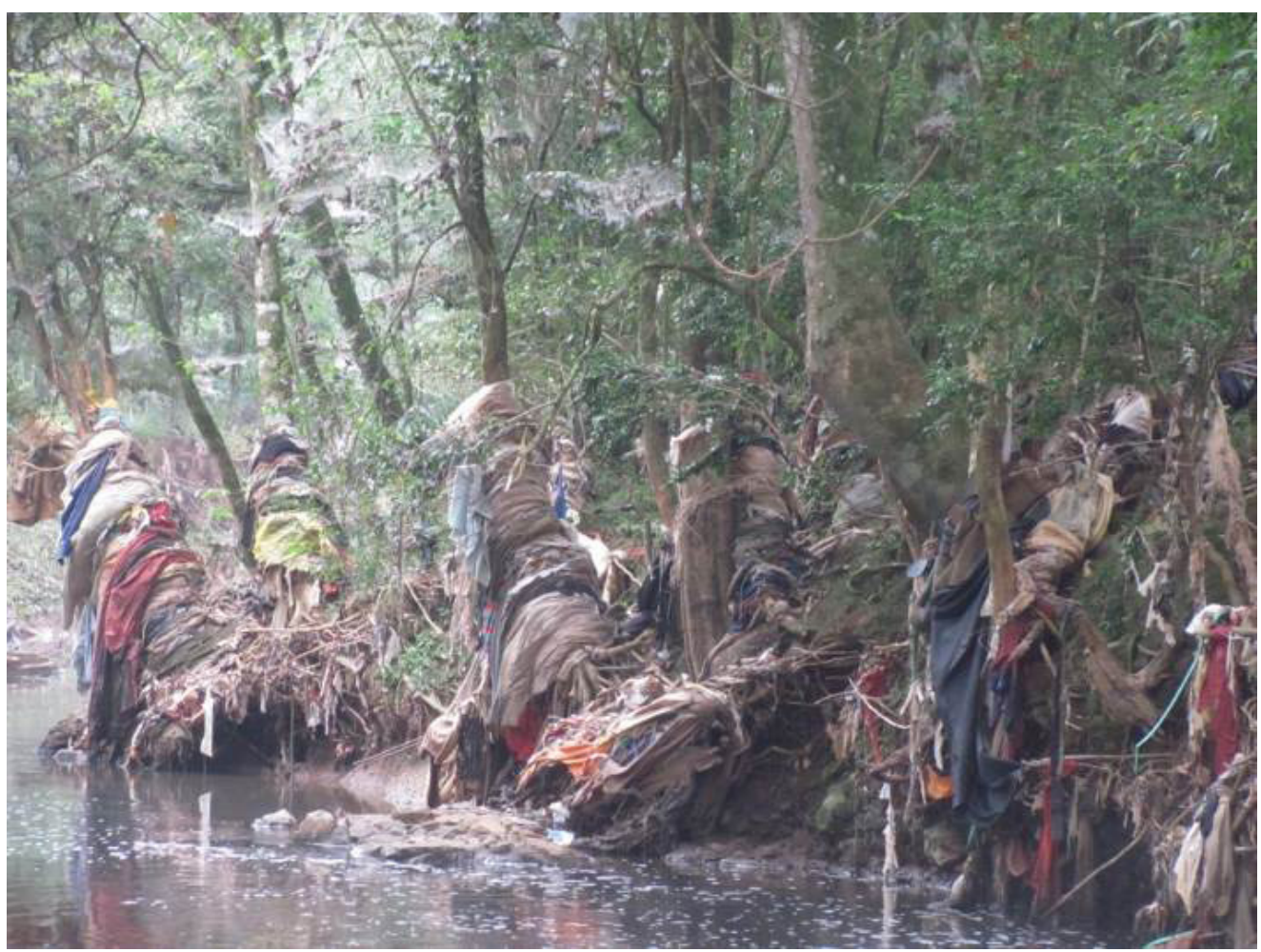

Figura 13--Realidade local do lixo jogado as margens do Rio Tigre Fonte: Eloverde, 2011.

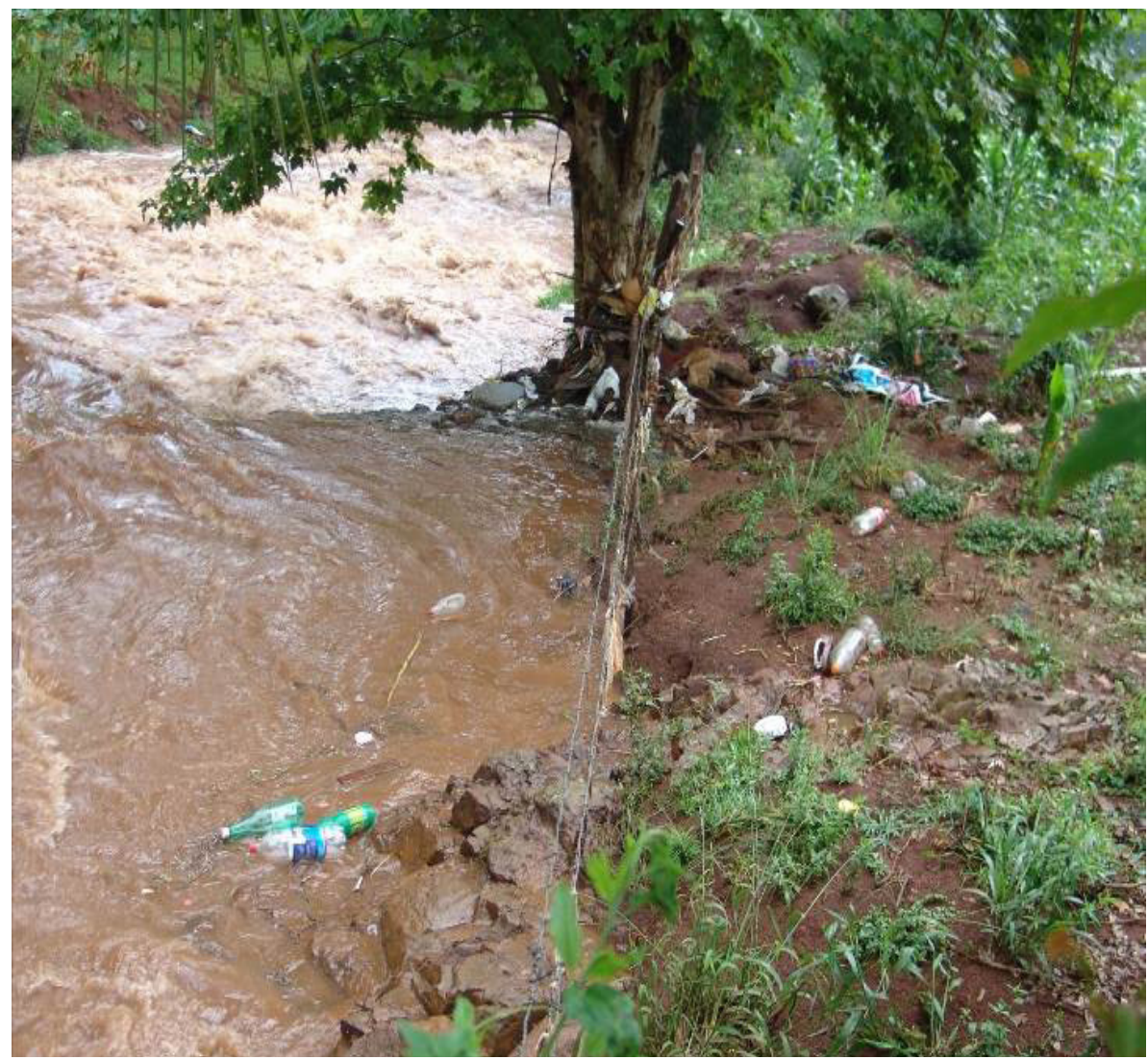

Figura 14- Rio Tigre eleito para receber todo o esgoto de Erechim.

Fonte Eloverde, 2011 
Conjunto: Etapa de Disposição Final.

No caso de Erechim, em função da escassez do manancial, é de bom censo disponibilizar de uma reserva estratégica, volume este a ser obtido ao longo do ano, principalmente no período das chuvas e que será suficiente para atender com segurança a demanda, sem considerar a reposição dos mananciais, que se sabe é baixíssima em períodos de estiagem.

\section{CONCLUSÕES}

Com este estudo procurou-se analisar a gestão dos recursos hídricos no município de Erechim (RS), com isso percebeu-se que o município conta com toda a estrutura física, institucional e legal e possui todos os elementos necessários para o gerenciamento do meio ambiente. No entanto uma das fragilidades identificadas é a falta de interação entre os órgãos atuantes, principalmente no que se refere a recursos hídricos.

Quanto ao uso dos Instrumentos de Gestão observou-se que o município, através do CBHAI elaborou o Plano de Ações em Recursos Hídricos, Enquadramento dos corpos hídricos em classe de usos preponderantes e já deu andamento para instalar no município a cobrança pelo uso da água. O município, através da SMMA, já utiliza o Licenciamento Ambiental e também elaborou os Planos Ambientais Municipais.

O Plano de Ações em Recursos Hídricos das Sub-Bacias do Arroio Tigre e Rio Campo, elaborado pelo CBHAI, contém as ações a serem executadas para recuperar e conservar os recursos hídricos e a cobrança da água irá contribuir para financiar estas ações e induzir o uso racional da água, além disso, todo dinheiro arrecadado deve ser utilizado na própria bacia hidrográfica em ações de gestão (capacitação e educação ambiental), planejamento (realização de estudos específicos) e ações estruturais (recuperação de nascentes, melhoria da qualidade das águas) etc.

Atualmente o município tem os planos ambientais, mas os mesmos não foram amplamente discutidos com a comunidade e os projetos propostos têm que vir a transformar-se em ações concretas. Notou-se a necessidade de se colocar em prática um programa de Educação Ambiental permanente e com ações efetivas. É necessário ainda divulgar nos meios de comunicação informações claras e objetivas sobre as unidades de conservação existentes no município e as normas de utilização desses espaços.
Sugere-se fazer uso da tarifação poluidor -pagador e utilizar forma mais eficiente o Sistema de Informações sobre recursos hídricos, pois as entidades atuam de forma isolada. Há que se criar parcerias com empresas privadas, ONG'S, universidades, prefeitura e comunidade para juntos atuarem na gestão ambiental do município de Erechim.

Inexiste no município, sistema público de tratamento de esgotamento sanitário, os contratos assinados pela Corsan e Prefeitura Municipal não vêm sendo cumpridos e não há nada de concreto, nada que garanta que isso aconteça no tempo previsto.

No abastecimento público há dificuldade devido às intensas mudanças climáticas, aumento da população, atividades antrópicas, os rios serem de pequeno porte e há prognóstico de continuar a ocorrer estiagem com racionamentos. A população tem como ônus o custo social e ambiental pelo não planejamento, falta de ações e não cumprimento dos contratos.

Quanto à transposição do Rio Cravo percebe-se que não foram levados em conta indicadores econômicos, pois o investimento é alto e a vida útil estimada é muito curta ( 25 a 30 anos). Parece que a transposição será somente uma obra para remediar de forma muito precária o problema da escassez de água potável no município de Erechim.

O Conselho Municipal de Proteção ao Meio Ambiente não vem atuando de forma eficiente, técnica e dentro da legislação municipal. Por vezes é alheio as questões de cunho ambiental do município e há visível falta de organização interna.

Sugere-se um Curso de Formação em Gestão Ambiental para conselheiros (gestores públicos).

Sugere-se que o planejamento continue com foco na bacia hidrográfica, que sejam propostas através de legislação municipal normas mais rígidas para concessão da outorga de uso da água, que sejam ampliadas as estruturas e capacidade para reservação de água em épocas de chuvas pela Corsan, aplicação de tecnologias voltadas para a redução de perdas e a realização de estudos científicos em parceria com universidades.

\section{REFERENCIAS}

CADERNO TÉCNICO ADESÃO AO SISTEMA INTEGRADO DE GESTÃO AMBIENTAL SIGA -RS /SEMA-RS, 2009. 
CARTILHA DO COMITÊ DE BACIA HIDRO-

GRÁFICA APUAÊ INHANDAVA, Erechim, 2011.

PELUSO, R.M.B. Economia Ambiental e Políticas

Públicas: uma Análise Situacional de Erechim no Rio Grande do Sul a partir dos anos 90. Dissertação de Mestrado, UFRGS, Porto Alegre, 2002.

PLANO AMBIENTAL MUNICIPAL, Erechim, RS, dezembro de 2011.

PLANO DE MANEJO DA ÁREA DE PROTEÇÃO AMBIENTAL DO RIO SUZANA, Erechim, RS, dezembro de 2011.

PLANO DE MANEJO DA ÁREA DE PROTEÇÃO AMBIENTAL DOS RIOS LIGEIRINHO E LEÃOZINHO, Erechim, RS, dezembro de 2011.

PLANO DE MANEJO PARQUE NATURAL MUNICIPAL LONGINES MALINOWSKI, Erechim, RS, dezembro de 2011.

PLANO DIRETOR DE ARBORIZAÇÃO URBANA DO MUNICÍPIO DE ERECHIM, RS, dezembro de 2011.

PLANO MUNICIPAL DE SANEAMENTO DE ERECHIM, Ampla, 2009. 